\title{
Telemedicine for Developing Countries
}

\section{A Survey and Some Design Issues}

Carlo Combi' ${ }^{1}$; Gabriele Pozzani' ${ }^{1}$; Giuseppe Pozzi²

${ }^{1}$ Dipartimento di Informatica, Università degli Studi di Verona, Verona, Italy;

${ }^{2}$ Dipartimento di Elettronica, Informazione e Bioingegneria, Politecnico di Milano, Milano, Italy

\section{Keywords}

Telemedicine, developing countries, medical records

\section{Summary}

Background: Developing countries need telemedicine applications that help in many situations, when physicians are a small number with respect to the population, when specialized physicians are not available, when patients and physicians in rural villages need assistance in the delivery of health care. Moreover, the requirements of telemedicine applications for developing countries are somewhat more demanding than for developed countries. Indeed, further social, organizational, and technical aspects need to be considered for successful telemedicine applications in developing countries. Objective: We consider all the major projects in telemedicine, devoted to developing countries, as described by the proper scientific literature. On the basis of such literature, we want to define a specific taxonomy that allows a proper classification and a fast overview of telemedicine projects in developing countries. Moreover, by considering both the literature and some recent direct experiences, we want to complete such overview by discussing some design issues to be taken into consideration when developing telemedicine software systems.

Methods: We considered and reviewed the major conferences and journals in depth, and looked for reports on the telemedicine projects.

Results: We provide the reader with a survey of the main projects and systems, from which we derived a taxonomy of features of telemedicine systems for developing countries. We also propose and discuss some classification criteria for design issues, based on the lessons learned in this research area.

Conclusions: We highlight some challenges and recommendations to be considered when designing a telemedicine system for developing countries.

\section{Correspondence to:}

Giuseppe Pozzi

Dipartimento di Elettronica,

Informazione e Bioingegneria,

Politecnico di Milano

p.za L. da Vinci 32,

I-20133 Milano, Italy,

Email: giuseppe.pozzi@polimi.it

\section{Appl Clin Inform 2016; 7: 1025-1050}

http://dx.doi.org/10.4338/ACI-2016-06-R-0089

received: June 11, 2016

accepted: September 19, 2016

published: November 2, 2016

Citation: Combi C, Pozzani G, Pozzi G. Telemedicine

for developing countries: a survey and some design issues. Appl Clin Inform 2016; 7: 1025-1050

http://dx.doi.org/10.4338/ACI-2016-06-R-0089

Funding

This work has been partially funded by Regione Veneto through the "Cooperazione decentrata allo sviluppo" program (CUP B48113000590003,

B42C14000270002), by the Department of Computer Science of the University of Verona, and by the Department of Electronics, Information, and Bioengineering of the Politecnico di Milano. 


\section{Introduction}

Several definitions of "telemedicine" have been presented by the literature so far: the WHO (World Health Organization) in 2009 counted 104 distinct, peer-reviewed definitions of the concept [1]. We refer here to telemedicine as "the delivery of health care services, where distance is a critical factor, by all health care professionals using information and communication technologies for the exchange of valid information for diagnosis, treatment and prevention of disease and injuries, research and evaluation, and for the continuing education of health care providers, all in the interests of advancing the health of individuals and their communities" [1].

The relevance of telemedicine is evident, just from reading its above definition. Whenever distance impairs the proper care to be delivered to a patient, telemedicine can be a good answer. Distance may affect the delivery of the care, both in time and in quality, everywhere. Both developed and developing countries may experience situations where the intervention time, from disease detection to beginning of care, seriously affects the final result of the care itself. Such typical situations range from acute myocardial infarction to cranial hemorrhage or to wounds or injuries affecting patients in rural locations. Both developed and developing countries may experience situations where quality of care seriously affects the final result of the care itself. As an example, if the resolution of a medical diagnostic image transmitted to the hospital from a rural location is poor, some lesions or anatomical districts affected by the disease or by the injury may go undetected, again compromising the final result of the care. As a matter of fact, all the countries, both developed and developing ones, can take real advantages from telemedicine.

According to the definition above, telemedicine can also be concisely referred to as "the use of information and telecommunication technologies (ICT) in medicine" [2]. Telemedicine is just not only for remote monitoring or diagnosing a patient (comparative performance of seven long-running telemedicine networks delivering humanitarian services [3]): it also includes e-learning techniques (to remotely deliver education both to health care workers and to patients), and teleconsultation (aka telecounseling or expert second opinion) services. This latter refers to any consultation between doctors or between doctors and patients on a network or video link (e.g., Facetime, intranet, Internet, Skype, etc.), as opposed to the "in person" counseling where no ICT is needed to manage the interaction between the patient and the physician(s).

In developed countries several programs have been deployed, and they have been promptly reported for 10-15 years (e.g., in the United Kingdom [4, 5], in Finland [6], in Europe [7], in Taiwan [8], and world-wide [9]). Some more recent programs were devoted to include also medical education, such as in Western Australia [10], where the program has been mainly used for remote education (76\% of the considered cases), without neglecting other goals such as wound cases (55\%), and psychiatry cases (54\%), and store-and-forward ECG (ElectroCardioGraphy) recordings.

To provide the reader with an economic evaluation of the effort, the telemedicine market in Europe increased from an amount of $€ 4.7$ billion in 2007 to the amount of $€ 11.2$ billion in 2012 - the European Commission (EU) estimates [11]. Additional world-wide estimations [12] assert that the global telehome and telemedicine market reached an amount of US\$13.8 billion 2012, US\$16.3 billion 2013, US\$ 19.2 billion 2014, and this market is expected to grow up to US\$ 35.1 billion in 2018, US\$ 43.4 billion in 2019, with a compound annual growth (CAGR) of $17.7 \%$. Some more estimations [13] evaluate that the European telemedicine market grew from US\$ 3.1 billion in 2010 to US\$ 4.8 billion in 2011, and will almost triple to US\$ 12.6 billion in 2019 at a CAGR of $12.82 \%$; at the worldwide level, the market of telemedicine reached an amount of US\$14.4 billion in 2015, and is expected to grow up to US\$ 34.0 billion in 2020 , with CAGR of $18.6 \%$.

Much less effort has been spent for similar initiatives in developing countries. Probably, this is due both to the much smaller return of investment (ROI), to a limited budget available, and to the greater difficulties expected or encountered also due to the lack of technological infrastructures. Moreover, while telemedicine programs in developed countries in most cases may easily deploy an emergency strategy, such as sending out an helicopter to rescue the patient and to transfer him/her to the nearest hospital in a very short time, similar situations in developing countries are generally more expensive and much harder to be deployed. Finally, in developed countries, telemedicine is side-by-side to more conventional health care, completing it, while in developing countries telemedicine in most cases is an alternative, or even the only alternative, to conventional health care. 
Nevertheless, telemedicine applications in developing countries could be a leverage to provide wide populations with basic health care services and to close the distance between rural areas and specialized hospitals usually located in big cities.

Efficacy and the cost-effectiveness of telemedicine compared with conventional health care still are to be properly evaluated [14]: in fact, major aspects to be considered include the amount of saved lives (e.g., some people would have died without the aid of a telemedicine system), and the quality of life of saved people (e.g., some people would have been completely restored if the telemedicine system could suggest them a first-aid assistance). As for the cost-effectiveness, to the best of our knowledge, Wang et al. [15] are the only ones to measure the economic benefits achieved by a telemedicine program: they just sum up the travel costs to move a specialist physician from a main hospital to the remote hospital, or to move the patients from the remote hospitals to the main hospital.

According to the previous considerations, telemedicine applications in developing countries need to be studied, designed, and evaluated according to specific criteria, which have to take into account cultural, environmental, organizational, and economic peculiarities of the considered countries and populations. Thus, the goal of this paper is twofold.

- First, we introduce a taxonomy, according to which we classify the main telemedicine projects in developing countries. Our taxonomy considers explicitly the specific features of telemedicine systems, when designed for developing countries. We then complete and make concrete such a taxonomy by using it to provide an overview of some major projects for telemedicine, particularly focusing on the specific needs of developing countries.

- Second, as a specific feature of this survey, we integrate - and in some sense extend and complete - the proposed taxonomy with a classification and discussion of design issues to be considered both for systems and tools, when dealing with telemedicine software for developing countries. Such a classification has been derived both from the considered literature and from our direct experiences in a recent project [16].

The paper is structured as in the following. Section 2 provides the reader with some criteria according to which existing projects can be classified and reviewed. Section 3 summarizes the state of the art in the field of telemedicine, considering the most relevant projects as described in the literature and providing their classification according the proposed taxonomy. Section 4 highlights some criteria we suggest when facing the design of a telemedicine project. Experiences and skills we gained in an ongoing telemedicine project guide the discussion of such criteria. Section 5 discusses and summarizes the major aspects and recommendations we believe fundamental in developing a successful telemedicine project in developing countries. Section 6 sketches out some conclusions, by summarizing the considered approach and the most relevant results of this work.

\section{A Taxonomy for Projects}

The state of the art of telemedicine programs in developing countries comes from many different sources. In order to identify the most relevant sources of information, we started by performing a query over the PubMed bibliographic system [17], by the keywords "telemedicine" and "developing country". This resulted in a set of publications, including some 500 papers both from journals and conferences. We also performed a similar query over the DBLP computer science bibliography web site [18], which is more prone to the computer science and engineering scientific research.

In order to select the major sources of information, we grouped the results according to their respective publishing location. By analyzing the results of these two major queries, we identified that the most focused journals on the topic are the IEEE Transactions on Information Technology in Biomedicine (IEEE T-ITB), now renamed as IEEE Journal of Biomedical and Health Informatics (IEEE JBHI), the Journal of Telemedicine and Telecare, the Telemedicine Journal, the International Journal of Medical Informatics, the Applied Clinical Informatics journal, and the Telemedicine and e-Health journal. The major and most relevant conferences on the same topic are the Annual Conference of the American Telemedicine Association, the European Telemedicine Conference, the Annual International Congress on Telehealth and Telecare, the eTelemed, and the mHealth + Telehealth World. Given this set of publishing locations, we manually scanned the last 3 decades of publi- 
cations, selecting those strictly related to the topic: we also checked the citations included by these papers, possibly capturing some additional papers on the topics of interest and published elsewhere. In this way, we built up a list of the papers we considered by the current survey.

Finally, since some of telemedicine projects in developing countries are carried out by private or non-governmental organizations (NGO), and thus not always reported by the specific scientific literature, we also used some commonly available search engines to look the web for reports on such projects and initiatives, and identified some projects which were not considered by the above mentioned scientific literature.

We also searched for previously published taxonomies and classification criteria for telemedicine projects. The major reference we identified on this topic is [19], which dates back to 2005. This paper by Tulu et al. focuses on telemedicine in general, without distinguishing projects deployed for developed or for developing countries: moreover, only few technical details are considered, such as application purpose, size of the hospital/healthcare center, bandwidth usage, type of connection (synchronous vs. asynchronous), and no other dimension is considered by the taxonomy.

One more taxonomy by Tulu et al. [20] in 2007 identifies five major dimensions of classifications: application purpose, application area, environmental setting, communication infrastructure, and delivery options. Again, no distinction applies on project targets between developed and developing countries, and no particular technical detail is considered.

By reading the volumes of the selected journals and conferences over the last three decades, several classification criteria can be adopted to categorize the projects in the field. Focusing on the projects, only, and thus disregarding the systems and the deployed tools whose details generally are not reported by the literature, we highlight here some possible categorization dimensions:

\section{Goals}

Moving from the above definition of telemedicine, several goals can be identified for a telemedicine project, and one project can be aimed at one or more goals. Major goals include:

- Remote diagnosing and teleconsulting system. Data (including signals and images) are locally (patient-side) acquired and stored, and then forwarded to the main hospital, where physicians can analyze those data. The remote (physician-side) hospital will then send back the diagnosis.

- Remote diagnosis can be performed even if patient is assisted by nurses, only, and no physician is in the neighborhood: such a situation typically occurs in rural locations of developing countries, and in some cases a preliminary diagnosis is locally performed by the aid of a decision support system (DSS). Teleconsulting, i.e., expert second opinion, is performed among physicians, where a non-specialist physician requires a remote consultation with one or more specialist physicians: typically, such a situation occurs in emergency centers of rural locations or in minor hospitals of developed countries, or in any location of developing countries.

- Remote monitoring system. The patient is monitored in the remote location, his/her signals are continuously acquired, forwarded to the main hospital, and, possibly, locally analyzed by a DSS. Alarms are remotely detected and transmitted back to the patient-side. The monitoring system can be managed and locally controlled by a physician or by a nurse.

- Remote intervention system. The patient enters the operating room, the intervention is performed through a local (patient-side) robot that is remotely controlled by a physician in the main hospital. The remote intervention requires that some local assistance is performed by a physician or by a nurse.

- Remote education (e-learning) system. Students or caregivers (mostly physicians, nurses, and technicians) attend classes taught from remote academic institutions, and possibly by a bi-directional communication interact with the teacher by making questions. Remote education can be locally assisted by a local tutor, during and/or after the classes.

\section{Country}

Developing countries are not an exclusive deployment field for telemedicine projects: they can be fruitfully deployed also in locations where resources are limited or some external constraints apply, such as airplanes or maritime media [21, 22, 23], as well as to reduce the overwhelming costs of a National Health Service [4]. An accurate evaluation of the real savings for the National Health Service (NHS) is a very challenging issue, also considering that the amount of the gross domestic prod- 
uct (GDP) one nation may devolve to the service varies a lot inside every nation. A few follow-up studies exist on the efficacy of telemedicine programs in developed countries (e.g., in Finland [6]), where other techniques different from telemedicine can be deployed: on the contrary, in developing countries, whose GDP is remarkably low if compared to the GDP of a developed country, no alternative seems to exist to telemedicine.

In the following, we further distinguish between emerging countries (aka as BRICS - Brazil, Russia, India, China, and South Africa) and developing countries. According to the World Bank [24], GDP is the proper figure of merit to distinguish emerging countries still have a GDP (or a per capita income) comparably low with respect to developed countries (i.e., a GDP per capita per year smaller than US\$ 12,475), however they are rapidly growing up and reducing their gap from developed countries; developing countries, instead, still lack a growth in their GDP and per capita income, showing a much more critical situation (i.e., a GDP per capita per year smaller than US\$4,035).

\section{Economic effort required/investment}

Developed countries feature a much greater gross domestic product (GDP) with respect to the GDP of developing countries. Public expenditure on health, measured as percentage of the GDP devoted to health care, differs even more between developed and developing countries, ranging from a ratio between 5.5 and 7.0 for the richest countries to a ratio between 0.6 and 1.7 for the poorest countries $[25,14]$.

Some more studies over the decades from 1995 to 2014 report a ratio between 5.9 and 7.7 for high income countries and a ratio between 1.5 and 2.4 for low income countries [26]. It can be easily observed that such a difference in economic resources and investments will characterize any telemedicine project, in terms of complexity, diffusion, accuracy, performance, number of considered cases to mention just few of them, only. Moreover, a low percentage of citizens in developed countries relies on telemedicine as the only medical care system: instead, a remarkable percentage of citizens in developing countries looks at telemedicine as the only medical care system, and the population coverage can be considered a good index of how effective the telemedicine project is.

\section{Location/environment}

Two main location types can be classified as: rural locations, where needs are mainly devoted to primary health care, including emergency situations $[27,28]$ and where we mainly observe first aid centers, often with no specific equipment to manage injured people; and urban locations, where needs are mostly oriented to chronic (and seldom congenital) pathologies, and where we expect to observe hospitals with some equipment for signal and image analysis. While citizens in developed countries mainly live in urban locations, a much higher percentage of citizens in developing countries still live in rural locations: a good estimation asserts that some $40 \%$ of people in Africa still live in rural locations [29], and telemedicine is the only chance of a medical care for such people.

\section{Infrastructure}

The main aspects on the infrastructure side cover the pure ICT technological infrastructure as well as any other generic infrastructure such as power supply, water supply.

In fact, generic infrastructures that can limit the results of the projects refer to: poor-quality electricity supplies (e.g., the average electric power consumption in Sub-Saharan Africa is $124 \mathrm{KWh}$ per capita per year, only a tenth of what found elsewhere in the developing world, and barely enough to power one 100-W light bulb per person for three hours a day [29]); poor-quality water supplies; poor-quality telephone services; isolation and lack of continuing medical education (CME) for health care staff; and poor supervision of health care staff [30]. In rural regions of developing countries, communication media [31] mainly include voice (typically, via a VHF transceiver) and text (typically, via e-mail messages), while rural regions of developed countries feature very different and more powerful communication media.

It can be easily observed that the infrastructure dimension mainly affects developing countries $[32,33,34]$, while developed countries featuring very good infrastructures are less impaired by this dimension. The WHO Global Observatory of eHealth reports recent trends and developments in telemedicine based on a survey of 114 Member States. Developing countries in Africa, the Americas, and South-East Asia cited infrastructure as one of the greatest barriers to telemedicine. In Africa 
alone, fifty percent of the responding nations believed infrastructure to be a barrier to telemedicine in general [1], and in particular to teleradiology in the Sub-Saharan area [35].

\section{Organization}

The main aspects on organization refer both to human resources (personnel) and to resources in general. As already identified about the above goals, the remote organization may feature nurses, only, or non-specialist physicians: it can also happen that the organization cannot deploy enough doctors and other health care workers, or that too many patients daily attend the care center. On the general resource point of view, major issues concern the lack of medical supplies, especially drugs, poor referral system (and usually no feedback to the person originating the referral), and lack of transportation [30]. Generally, these issues for the organization are critical in developing countries, while developed countries are not expected to experience them - or experience them very seldom.

\section{Maturity}

A project during its life-cycle goes through some states. Typically, the major states include designed, early stage, under completion, completed or ceased, continuously running. The preferable state is obviously that of continuously running, meaning that the project is still active and successful, and that the advantages produced by the project are still evident.

\section{Success rate and SWOT (strength and weakness of treatment) analysis}

It is generally observed that most telemedicine projects are successful as long as the financial support is conspicuous, and this typically occurs at project onset time: after the initial honeymoon, most projects reduce fund availability and, consequently, projects decline as time goes by. This aspect is even more enhanced and evident if the training personnel abandons the trained personnel after some time, letting the trained personnel to continue the project on their own. A good evaluation of the project and of its success is the lifespan of the project [36].

\section{Effectiveness of the project for the patient care}

The project would enable the investor, typically a National Health Service, to save money and to increase the quality of care. While measuring the effectiveness is extremely hard, it could be easier to count how many patients have been treated (and how many saved) among those who would have not been treated at all if no telemedicine system were deployed. Other ways of measuring the effectiveness are those of considering the overall expense and the time required to deploy the system.

\section{Innovation}

(i.e., innovative versus pragmatic). Projects can be completely innovative (e.g., introducing workflows that formally model the care process) or pragmatic (e.g., following traditional approaches). Typically, a successful project includes some innovative novelties and some pragmatic features, so that users can be attracted by the good flavor of the novelty and they are confident that results will be granted by the traditional way of managing patients. That is, a good balance and compromise between innovation and traditional existing operations can be the key issue for a successful telemedicine project [36].

As we already stated, the above criteria mainly refer to projects in general, and do not focus on the systems and the tools available for the projects themselves. We highlight here some further categorization dimensions for the systems and the tools:

\section{Hardware requirements}

Basic requirements for the hardware cover a wide variety of aspects such as power consumption and, possibly, power generation, air conditioning, and number of involved workstations. While most of these requirements are not critical for telemedicine projects in developed countries, the same requirements can be critical in rural locations, and even in some urban locations, of developing countries. 


\section{Communication requirements}

Any telemedicine project may experience severe bottlenecks from the communication infrastructure. Major communication requirements include the bandwidth of the network architecture. The bandwidth seriously impacts on the communication type: a reduced bandwidth enables asynchronous communications only, while synchronous communications require a larger bandwidth; a reduced bandwidth enables transmitting simple information, mainly textual one, while a larger bandwidth enables one to transmit more complex information, including voice, sounds (e.g., stethoscope), still images, dynamic images and movies. As for the hardware requirements, most of the communication requirements can be critical in developing countries, both rural and urban locations.

Architectural issues may enrich the communication requirements, too: in fact, multipoint-tomultipoint communication is sometimes needed, which is much more powerful than a simple point-to-point architecture, particularly when critical cases may require different teams of expert to be involved in the discussion [37].

\section{Software requirements}

Basic software requirements have to consider both the main location, typically the big hospital running as the server of the telemedicine service, and the remote locations, typically the rural locations and/or the developing countries running as clients of the telemedicine service.

Major limiting requirements come from the client side. We distinguish if the telemedicine service in the client side involves one unique remote workstation, e.g., one PC, or more remote workstations, e.g., one PC and other biomedical instrumentation such a bio-signal recorder or an imaging device. Moreover, some local workstations in the client side can be locally connected through a local area network (LAN): consequently the remote server type and architecture (open vs. proprietary), the operating system (typically, Linux or Windows), the provided services (printer spool, document sharing, proxy, firewall, security and user log-in and authentication), and the number of deployed workstations must be considered.

Other minor issues concerning the software requirements must be considered, such as scalability and customizability. Moreover, if a limited budget is available, the difference between commercial software and public domain/freeware/shareware becomes extremely relevant.

- Figure 1 depicts a concept map, which summarizes the main aspects of the proposed taxonomy.

\section{Telemedicine Projects: Applying the Taxonomy}

A very large number of telemedicine projects have been deployed so far. Major sources of information about them are some scientific journals, some scientific conferences, and the reports from the WHO focused on the topic.

In this section, we report on the most recent projects, dividing them according to the size of the nation or of the scenario where the project has been deployed.

\subsection{Case Studies}

Major case studies involve big nations and/or wide regions. Among them, we consider here the following ones:

\section{China}

Despite its rapidly growing economy, the overall health systems performance of China is ranked 144, as of 2007 [38]. In China [38] 20\% of the resources are available to 900 million rural people, which represent some $70 \%$ of the entire Chinese population (as of 2007, no further studies available).

Most projects involve a rural hospital, connected to a responding site which generally is a large hospital in China. Signals, diagnostic images, and videos are acquired in the rural hospital during a first visit, sent to the large hospital, and then diagnosed and evaluated by the remote specialist. 
One of the most relevant projects covered the Sichuan area (West China) from 2002 to 2013 [15]: the telemedicine network connected some 249 spoke hospitals in 112 rural cities with some highly specialized urban hospitals, focusing on 40 medical expertise areas. During the 12 -year period, some 11,987 teleconsultations were performed, mainly devoted to diagnosing neoplasms, injuries, and cardiovascular diseases. Interestingly, Wang et al. in this study report some quantitative measurements of achieved results, thus proving a real efficacy of the telemedicine project: $39.8 \%$ of the original diagnoses were modified after the teleconsulting; 55\% of the original treatments were modified after the teleconsulting. The authors also sum up the net saving of some US\$2.3 million for patients (diagnosed in the rural hospital, patients did not need to move to the main hospital) and of some US\$ 3.7 million for specialists (specialists did not need to move to the rural hospital to complete the diagnosis or to validate the treatment).

The current (2014) Chinese technological infrastructure has greatly improved the communication quality of the telemedicine projects, and most rural locations are now (2014) covered by a good communication infrastructure. Major encountered difficulties refer to the conflicts of telemedicine with traditional medical culture in China, which is mainly based on face-to-face interaction. Next, physicians are not economically motivated to switch to telemedicine, and prefer continuing with traditional approaches. Moreover Chinese hospitals lack personnel to maintain telemedicine systems. Finally, lack of standard on health data prevents a successful deployment of telemedicine projects [38].

\section{India}

The situation [39] features a very high number of rural locations, where some $80 \%$ of its main health-care centers are in urban locations which host some $30 \%$ of the population. Consequently, the $20 \%$ of the overall national facilities, mainly managed by inexperienced professionals in rural locations, have to take care of some 770 million citizens.

In India the life expectancy at birth is of 52 years, and the technological infrastructure reaches over $65 \%$ of the Indian landmass and $80 \%$ of its population. The percentage of GDP devoted to health-care is estimated to be $4.9 \%$ (as of 2005).

The main telemedicine projects are known as Apollo, Otri, and Asia Heart Foundation. All of them mainly involved Indian national locations, and focused on major needs from cardiology, emergency, radiology, ophthalmology, and nephrology departments. Signals, diagnostic images and videos are transferred among workstations based on Intel computers: some peaks of 750 sessions per month have been achieved, thus proving a real deployment on the field for the project.

Major difficulties encountered by the projects are bureaucracy and protectionist policies [39], despite the provided services were free and recipients have been generally satisfied with the projects. In order to manage some of these difficulties, several efforts were spent, e.g., to improve the quality of user-friendly interfaces, including translating the Linux operating system to the national official Hindi language, and to increase the coverage of landline connectivity in a very big nation featuring low teledensity levels.

\section{Sub-Saharan Africa}

With a population of some 725 million inhabitants, the Sub-Saharan Africa (SSA) [35] region is severely affected by HIV/AIDS (some $70 \%$ of the 40 million worldwide people suffering from this disease live in the SSA), and by malaria (killing more than 1 million children every year). The physician-to-population ratio ranges from 1:5,000 to 1:30,000, while in developed countries the typical ratio is 1:300 [35]. All of these conditions suggest that telemedicine can substantially improve the quality of health-care.

The main projects over the last decade in the SSA include: transmission of biomedical images among the four major hospitals in Senegal; schedule consultations and referrals in Ethiopia; share scientific literature about cholera epidemic infections in Zambia; provide local physicians in Ghana with education on malaria from hospitals in London, UK and Geneva, Switzerland; provide patients in Congo with a remote assistance on diagnosis, treatment, and follow up by physicians of the Luigi Sacco Hospital in Milano, Italy; and, exchanging medical records and images between two major hospitals in Mozambique by a direct microwave terrestrial link set up by ITU (International Telecommunication Union) in 1998. 
Major difficulties encountered refer to poor national ICT policies (e.g., some nations including Burundi and Ethiopia have extremely low public expenditure on health care, in the range between $0.6 \%$ and $1.5 \%$ of the GDP [14], and in some cases include high tax policies on already very expensive medical instrumentation), very limited ICT infrastructure (despite the number of mobile subscribers has been observed to grow up at a rate of $82 \%$ a year), implementation factors (e.g., obtaining top management support locally, and training local trainers for sustainable long-term support), and cultural differences among the users involved in the projects (e.g., Cameroon has a population of 14 million with 279 distinct languages).

\section{Egypt}

With a population of some 85 million inhabitants, Egypt has significantly improved its technological infrastructure, with some 91.32 million mobile subscribers (as of January 2012) and a mobile penetration rate of $112.30 \%$ (some subscribers having more than one line). Egypt had 29.53 million Internet users, while Internet penetration rate was 36.31\% (again as of January 2012). Egypt hosts 12 major nation-wide hospitals. The main projects in Egypt [40] covered the decade 2002-2012, and involved:

i. Diagnosis of relevant pathologies (an inter-hospital teleconsulting project established in 2002 between the Italian Hospital Umberto I in Cairo and the ARNAS-Civic Hospital of Palermo, Italy, considering both biomedical images and ECG signals for a second opinion service, both in real time and in off-line mode).

ii. Prevention and treatment of the common diseases in the participating countries, including Egypt, Ethiopia, Jordan, Libya, Mali, Morocco, Sudan, Tunisia, and Uganda in 2006.

iii. Egyptian Telemedicine Network (ETN) to provide the Egyptian population with a range of medical services, including radiology, electronic stethoscope, tele-pathology and ECG.

iv. Improving health care services for children by providing teleconsultation in addition to lifelong professional training of doctors via eLearning techniques in 2009.

v. Teleconsultation services for diagnosis and treatment of infectious diseases, like hepatitis, for under-served regions in Egypt in 2009.

vi. Pan Africa Project providing Teleconsulations services through conducting video-conference sessions between the health care organizations in Alexandria (Egypt) and 12 hospitals in India in 2009.

vii. Women health care Mobile Unit Project in 2007, to screen ladies above 45 years using fixed and mobile digital mammography imaging units.

viii. Egypt national PACS in 2010, setting up a centralized Picture Archiving and Communication System (PACS) covering the six major hospitals in Egypt.

Major difficulties encountered by the projects in Egypt include the technical, financial, and human resources aspect [40]. Other encountered difficulties include the resistance to change (which faces many of health informatics applications), the unclear business model for telemedicine (i.e., which services could be provided, who will pay and how much will be paid), the unavailability of an efficient infrastructure for telemedicine (high bandwidth and the special equipment) in the rural areas, and the unavailability of regulatory bodies for accrediting telemedicine eHealth systems and health care organization, and for issuing best practices and guidelines.

\section{Pacific Islands and Micronesia}

The area features some peculiarities, which make it very unique [41, 42]. In fact, the total population of some 160,000 inhabitants is spread over 97 islands, villages are densely populated, while some 2,000 islands are not inhabited. The population is very young, estimating that $45 \%$ of the population is under 15. The experiments of telemedicine date back to 1996, and were mainly devoted to remote medical education. No more recent projects seem to have been started in this area.

Considering both the extremely limited number of inhabitants, as well as the very low GDP for the area, some indexes, such as percentage of GDP devoted to health services or percentage of population covered by health services, lead to quite unusual values if compared to the respective values of other countries. 


\section{Amazon region of Peru (rural)}

The region is strictly rural, sizing twice the area of Belgium, and it is accessible by river, as very few roads exist [31]. Average size of villages is smaller than 100 inhabitants, and no telephone line exists, generally.

The main project started in 2001 and aimed at setting up an e-mail connection between 39 previously isolated health facilities and the main hospital in Lima. Connections are based on VHF radio channels, and significantly helped in reducing the patient's evacuation time, from an average value of 8.6 hours to as low as 5.2 hours. The overall costs of the project are very limited, as expenses are mainly due to electric power consumption and to maintenance and repair of radio devices.

- Table 1 summarizes the main features of the major projects in developing countries we described in this section, according to the dimensions proposed in the taxonomy discussed in Section 2.

\subsection{Minor Case Studies}

Minor - although relevant - case studies, which involve small nations and/or narrow regions, include:

\section{Brazil}

The Government of Paraiba (North-East of Brazil) started a telemedicine project for remote screening of hearth defects in children [43], over a global population of some 3.7 million inhabitants. Some 73,751 children were analyzed in remote health facilities during 2012-2014. In case of uncertainty, echocardiographic examinations were then sent over the Internet to a cardiology team made of 7 cardiologists, 3 residents, and 4 staff, providing a 24/7 assistance: if needed, a cardiologist was sent back to the remote health facility. Some 857 congenital diseases were identified - most of them would have remained undetected if no telemedicine program were deployed - and treated.

This telemedicine project required an initial investment of some US\$1.2 million for the first year, covering 12 major centers: the annual cost increased to US\$2.0 million in the second year, extending the project to 21 centers and services.

\section{Zambia}

The Nexus Mundi Foundation [44] in Zambia takes care of the Chikuni Mission Hospital, where one physician and some nurses manage a 95 bed hospital. The hospital serves some 180 small villages, thus covering a strictly rural area.

The telemedicine project sets up a teleconsulting system, which also enables the staff of the hospital to access historical data of patients, basically consisting of lab exams and X-ray images stored in remote facilities.

The project is partially funded by Telecom Italia, France Telecom, Inmarsat, ministries of the Italian and French Governments, and international organizations including ITU, UATI, and G-7.

\section{Balkans}

The Italian association Cuore un Mondo, in cooperation with the Ospedale del Cuore, Massa (Italy), the Tuscany Region (Italy), and the CNR of Pisa (Italy) developed a teleconsulting system based on open source systems [45].

Three major hospitals in Bosnia Herzegovina, Croatia, and Albania are connected to the headquarter in Massa for real-time interactions and teleconsulting with specialists in the field of congenital heart diseases. Other services include video-conferencing, DICOM image transmission, and data storage.

Major feature of this project is the deployment of open source systems, only. These systems include LAMP (Linux, Apache, MySQL and PHP) servers, Ekiga for VOIP communications, VLC for video and streaming playing, DCM4CHE for biomedical image storage, and Oviyam for DICOM images displaying. 


\section{Zambia, Congo, Madagascar (ZCM) and other regions}

The project from the Italian association Patologi Oltre Frontiera [46] aimed at setting up laboratories to perform preventive examinations to fight cancer in developing countries.

Micro and macro images are stored locally (patient-side), and remote consulting is performed by expert physicians from Italian hospitals. The web application also enables users to perform video conferencing.

Major feature of this project is that the server is local, i.e., patient-side, and remote experts connect via a web-browser. Most projects, instead, are generally based on a remote server (expert-side, and not patient-side) which receives connections from patient-side physicians.

\section{Burundi}

This telemedicine project, funded by the Veneto Region and by the University of Verona, considers requirement collection and analysis, design, implementation, and deployment of a prototype aimed at providing local physicians of the Hospital of Ngozi, Burundi, with expert second opinions from their colleagues in the University of Verona, Italy, on interpreting ECG signals, ultrasound and X-ray images. First experiments were done mainly focusing on teleconsulting for pediatric cardiology [16].

The project identified as fundamental requirement the involvement of local users - as many as possible. In order to avoid the major pitfalls, the project provided the local users with the proper skills before deploying the system, and then performing a continuous follow up of the system and of its usage in the everyday practice.

For this reason, the project trained 20 nurses on how to better use the ECG machine, and 5 physicians on how to use the ultrasound system for performing echocardiographic examinations. Moreover, all of them, have been informed about the provided second opinion system.

The first time, the proposed system has been used during a screening of cardiovascular diseases performed in the first two weeks of August 2014. A radio message was broadcasted to inform the population of Ngozi about the possibility of being visited by Italian cardiologists. About 180 persons have been visited, identifying 25 suspected cases of rheumatic and congenital cardiovascular patients ( $50 \%$ of them were pediatric ones). Data and knowledge about suspected cases have been shared with physicians in Verona for a second opinion. Besides basic information and clinical notes, all shared consultations have ultrasound attachments (images and videos), and some of them have $\mathrm{X}$-Rays and ECGs, too. This screening and consultation process involved two physicians in Ngozi and four physicians in Verona. Some of the consultations confirmed the suspects and identified patients for surgical intervention.

Although the project focused on cardiovascular diseases, the proposed system has been used also to ask for a second opinion about cases of cancer, pneumonia, and laryngomalacia.

\section{Occidental Africa}

The project started by the University Hospital of Geneva, Switzerland, initially involved Mali in 2001, and then was extended to include Morocco, Tunisia, Cameroon, Madagascar, Ivory Coast, Niger, Burkina Faso and Djibouti [47, 48, 49, 50].

The main original goal of the project was remote education (North to South) for physicians in Occidental Africa, receiving education from Geneva, Switzerland. The project has then been enriched to cover remote consulting for pathologist, neurosurgeons, and oncologists. Education was extended, too, so that remote education could take place also among African countries (South to South) as well as from Africa back to Europe (South to North) for African and tropical diseases.

The project is based on an open source platform for remote consulting, namely iPath [50], developed at the University of Basel, Switzerland.

\section{Other case studies}

The literature considers many other case studies, which, however, are poorly described or cover a very narrow geographical area. Among the many existing projects, we mention here:

- A project in Sierra Leone, by the Italian Fondazione don Gnocchi [51], mainly devoted to remote education of personnel. 
- A project in Chad by the Italian Fondazione Cumse [52], mainly devoted to the prevention of endemic diseases like AIDS and malaria.

- A project in Ethiopia, by the International Telecommunication Union [53], related to teledermatology, teleradiology and telepathology.

- A project in Rwanda, by the National Information and Communication Infrastructure [54], involving three hospitals with video conferencing facilities to enhance a participatory approach in teaching, continuous medical education, and training of the personnel.

- A project mainly addressed to Africa [55], devoted to massive remote education on disease prevention (particularly, sexually transmitted diseases) and based on short message service (SMS) sent out to mobile phone users of the population. This is a one-way education, as no feedback is permitted from the addressees of the SMS.

- A project in the Middle East [56] (Iraq, Afghanistan, Pakistan, Kuwait), where physicians can ask for a remote consultation on critical cases by sending out e-mail messages to their colleagues in developed countries. The total number of considered cases is very limited (less than 800).

- A pilot project in Nepal [57] by the local government, involving some thirty peripheral district hospitals, mainly focused on the challenges in telemedicine. The project reported that major critical issues include infrastructure problems, lack of human resources, competence and financing.

Table 2 summarizes the main features of the minor projects in developing countries we described in this section, according to the dimensions proposed in the taxonomy discussed in Section 2.

\section{Design Issues in Telemedicine Systems}

Very few papers from the literature provide the reader with sufficient details about the design issues which drove the development of the projects described by the papers themselves. Systems and tools deployed during the project are generally neither described nor mentioned by the literature. Thus, the advantages as well as the pitfalls in using one technology or one product rather than another one, remain not revealed.

Moreover, very few models exist to categorize the systems and the tools that can be profitably deployed in telemedicine projects. The empirical evidence is very limited on the criteria according to which the proper technology would be selected, as Chan et al. write "there is a paucity of models and empirical evidence informing the technology selection process in these settings" in [58]. Rather than selecting the system or the tool according to their main features or to the requirements of the project, design experts apply filters which consider situational factors, technology and target patients, and the empirical evidence [58]. In this way, design experts derive the choices which will then determine the main functionality of the project - as well as its success.

Evaluating the deployed systems and tools, in order to identify some suggestions and recommendations for future similar initiatives in the field of telemedicine and telecounseling, is an extremely challenging task. By this paper, we do not aim at doing such evaluations (as done in 1999 by [59], in 2010 by [60], and in 2012 by [61]); we rather provide the reader with a set of features according to which the most proper systems and tools can be classified and, consequently, selected in order to have a proper design for the project.

The classification covers both the systems, referring to them as the complete environment for telemedicine, and the tools, referring to them as the components used to design and to build up the systems. The following taxonomy differs from the one we defined in Section 2 as the previous one referred to projects described by the literature and to the dimensions according to which one could categorize those projects: the following taxonomy, instead, focuses on the design issues to be faced when starting the design phase. As for the systems, the main classification criteria are (not limited to):

\section{i. Software architecture}

Several types of software architecture can be deployed. The most common are: 


\section{Web based}

This architecture basically requires a Web browser, only. While major advantages include ease-ofuse, non installation required, and multi-platform execution, some limitations apply, such as limited functionality and limited storage possibilities.

\section{Web app}

This architecture requires to launch applications, generally written in Java, within a Web browser. Most of the limitations of a pure Web based architecture are overridden by this approach: however, full and deep control over the application may lack.

\section{App}

This architecture requires to download an application and the run it directly, typically on most recent mobile systems such as smartphones and tablets. This architecture is providing full control of the processing system, including storage, transmission and vital sign analysis, and may also include advanced control logics.

\section{Remote app}

This architecture just requires a dumb terminal locally deployed, which connects to a remote processing system. All the control logics are defined and stored within the remote system.

\section{ii. Connection type}

The system can provide users with different types of connection:

\section{Point-to-point vs. multipoint connection}

More simple systems permit one to have a point-to-point connection, only: this means that two locations can be involved in the telemedicine communication at a time, only, and there is no way of simultaneously involving more locations. Typically, if the main telemedicine center in the developed county has to serve requests coming from two remote hospitals, the telemedicine center will first serve one request, then will close the connection with the first requester, and finally will open the connection with the second requester. Or, in a complementary situation, if the remote hospital has to discuss a critical case and needs assistance from two telemedicine centers from developed countries, the remote hospital has to connect with one telemedicine center, then has to close that connection, and finally has to open the connection with the second telemedicine center.

\section{Multipoint connection}

Conversely, more powerful systems permit one to have a multipoint connection: this means that users can simultaneously involve different centers for remote counseling, being either one telemedicine center connecting several remote hospitals, or one remote hospital connecting several telemedicine centers.

\section{Synchronous vs. asynchronous}

More simple systems provide users with an asynchronous connection, mainly based on e-mail messages. On the other side, more powerful systems provide users with a synchronous connection, which includes chat and voice;

\section{Transferred information}

Simple information that can be transmitted from the remote hospital to the telemedicine center (and, obviously, vice versa) are alphanumerical (text). More powerful system include voice and sound (e.g., typically sounds from the internal of the body are detected by auscultation), static images, and sequences of images and movies. Voice must have a synchronous transmission, preferably.

\section{Fixed versus mobile}

The terminal of the telemedicine system can be a fixed one or a mobile one. Typically, fixed terminals provide users with higher performances (e.g., video resolution of highest frame rates for video rendering), feature low portability (e.g., to move to the place where the patient is for a visual 
inspection by remote physicians), but require more resources - also in term of power consumption: this requirement can be critical in some situations in developing countries. Mobile terminals, conversely, feature a higher portability: typically, mobile phones mainly help in behavioral health interventions, and fail in real clinical situations [58].

\section{iii. Storage}

More powerful telemedicine systems provide the remote computers with redundant storage, so that failures (typically, hard disk failures) do not wipe all the information stored. In fact, hard working conditions (temperature, humidity, dust) may strongly challenge the computer systems: moreover, spare parts are hardly delivered to remote locations in developing countries, thus a redundant and fault tolerant architecture can permit a safer storage.

Preferably, the telemedicine system can also enable the remote system to locally store information from the other corresponding facility/facilities, i.e., the telemedicine center can make local copies of the files from the remote hospital(s) in the developing country, and vice versa. This permits the users to have an off-line analysis, too.

\section{iv. Technology acceptance}

The impact of the telemedicine system on everyday practice is absolutely relevant and must not be neglected. The results of the entire project strongly depend on the acceptance of the application and of the telemedical service, too. As for the acceptance, user interface obviously is one of the most important issues: however, local languages - especially in developing countries - must be suitably adopted, as the use of the local language may be the only way for a proper interaction with the local users. Furthermore, training of personnel on how to use the system is another fundamental issue to achieve a pretty good technology acceptance: in fact, the difficulties encountered at the very early interaction with the system may discourage further use of the system itself.

On the other side, the main criteria to classify the tools are (not limited to):

\section{i. Open source (vs. proprietary)}

Open source tools come for free but in most cases carry along a very poor assistance and documentation, making their use extremely challenging for relevant projects. On the other side, proprietary tools are generally expensive but more documented, constantly updated and maintained over time. Generally speaking, performance considerably differs between open source and proprietary tools, especially when the size and the workload of the project increase during project deployment, and resources need to be scaled up.

\section{ii. Lightweight, in terms of needed hardware resources}

The more resources are needed, the higher will be the cost of the overall system as well as the cost for keeping it running, also in terms of electric power consumption. If the project is to be deployed in a rural location or on a mobile facility (in order to have a wider coverage in terms of assisted population), the power consumption, together with network and telecommunication requirements, becomes one of the most relevant issues in terms of the real success for the telemedicine system. Generally, proprietary tools require more resources than open source ones - but many counterexamples exist.

\section{iii. Interoperability}

Interoperable tools can be easily interconnected each other, when developing the system. Interoperability calls for standard mechanisms for sharing and exchanging information among the modules, including file formats and remote invocation of procedures and services. Highly interoperable tools and higher interoperability levels provide higher information sharing, thus easily increasing the functionalities of the telemedicine system and the number of health care centers involved in the project. 


\section{iv. Scalability}

Scalable and extensible tools imply that the resulting system can be easily enriched to cover more cases, wider areas, greater population, more pathologies and more health care centers. In fact, the number of teleconsultations per month can be extremely low at the project onset, requiring a very limited set of resources. After tuning the components and staring up the project, the number of participants to the project - according to the spent efforts and to the success of the project itself - can increase very rapidly, thus requiring to enrich and to enhance the dimensions of the project as well as of the required hardware and software components.

\section{v. Flexible, adaptable, reusable}

These features of the tools enable the developers to achieve a final system which can be easily adapted and extended to cover wider application scenarios, in terms of more diseases or more treatments or more interventions that can be managed beyond those originally planned in the project, of a wider range of assisted population, and of a bigger number of health care centers involved in the project. Reusability enables the developers to deploy new systems moving by difference with respect to already developed one, thus reducing both costs - which is an extremely relevant feature, given that development budgets for projects in developing countries are very limited - and development times - obtaining the first prototype in a reduced time span.

\section{vi. Powerful yet easy to use}

Tools used in developing telemedicine systems would preferably be powerful, so that few instructions/commands achieve the required goal, and easy to use, so that developers do not need extensive (and expensive) training courses on getting skills on the used technology and tools [36].

\section{vii. Appropriateness}

The tools must be appropriate to the goals targeted by the project. More powerful tools are suitable for research-oriented prototypes and systems, and may lead to fragile applications: more reliable tools are suitable for systems deployed in the everyday practice, focusing on more robust applications.

A list of country-reported services provided through telemedicine is in [1].

While most systems for Electronic Medical Record (EMR) in developed countries are computerbased, most EMR of developing countries are paper-based. Very simple information management tools (FileMaker in [62]) may be a very good starting point.

A comparison of some teleconsultation systems, including DiViSy, DoctorPro, e-Consultant, Teleradiology.com, MedVizer, TeleConsult, Konsul are in [63]. A new prototype, namely TeleDI$\mathrm{COM}$, introduces new essential features, like multipoint-to-multipoint communication - although a very good bandwidth is required.

- Figure 2 depicts a concept map, which summarizes the main aspects of the classification we discussed for design issues related to tools and software systems.

\section{Discussion}

By considering the scenario summarized by $>$ Table 1 and $\$ Table 2, we are now able to draw some conclusions and then sketch out challenges, recommendations, and the lessons we learned.

All the considered projects include in the goals the "remote diagnosis", where some possibly include also further goals. This can be interpreted as an indicator of the main perceived requirement for telemedicine projects, no matter the size of the project itself. The second most common goal is "remote education".

While considered countries are all labeled as "developing", unfortunately there is no follow-up research on the continuing usage of the systems after the initial deployment and enthusiasm. However, very few projects in developed country feature a follow-up study, too: follow-up studies, aimed at evaluating the real advantages and usefulness of every project, are extremely complex, as too many 
success factors must be considered and suitably weighted to achieve a Success/Failure evaluation of the project.

Very few project reports describe the real economic effort spent in deploying the project itself: such data, which are generally expressed as percentage of the GDP, are reported only for a few of the major projects, and are not available at all for mid or small size projects.

The location addressed by the project is preferably rural for major projects, and urban for minor projects. One possible interpretation is that major projects, which require major economic efforts, can be deployed by countries whose economy is not extremely poor: such countries may have already given higher priority to telemedicine projects in urban locations, and - as a second intervention - have then focused on rural locations, which generally cover a reduce set of the overall population for that country. On the other side, minor projects come from poorer countries with a very restricted economy, and whose governments are now committed to providing urban locations with an health-service coverage: extending the project to rural locations is probably set as second-level priority for that country.

Success rate, even if the information is extracted from the description of the project as presented by the literature and not clearly stated, is not related to the dimension of the project.

Instead, hardware prerequisites and telecommunication requirements are strictly related to the dimension of the project: the bigger the project, the greater the prerequisites and the requirements. However, such a dependency between project size and the prerequisites and the requirements, is better read as a dependency between project size and location (urban or rural). In urban locations, hardware prerequisites and telecommunication requirements can be fulfilled more effectively and with a reduced economic effort than in rural locations. Consequently, as stated above, bigger projects come with bigger budgets and may focus on rural locations where higher power consumption and greater bandwidth availability result in a bigger economic effort.

\subsection{Challenges, Recommendations - Lessons Learnt}

We firstly focus on the main challenges to be faced by telemedicine projects, and then describe the major recommendations and the lessons learnt in the field.

\subsubsection{Major Challenges}

Major challenges, also coming from the literature [40], refer to:

\section{i. High cost of telemedicine systems and solutions, especially for rural areas.}

Low budgets are affecting all the projects of developing countries, also outside the strict health care sector. Maintenance costs for keeping the system alive after the original experimentation and enthusiasm, are even higher in developing countries if compared to the similar costs in developed countries. In order to achieve a good final result, some initial funds could be devoted to continuing the use of the system. Such considerations are confirmed by our taxonomy and by the survey based on it. Indeed, there is no evidence that the designed and implemented systems have been used after the end of the projects, even for those with significant economic efforts and high requirements, as depicted in Table 1 .

\section{ii. Resistance to change and slow clinical acceptance of telemedicine.}

A not negligible effort should be devoted to overtake the entrance barriers every new project has to face when entering the application domain. This is particularly evident - and must be properly managed - in the health care sector. General practitioners as well as specialized physicians are used to maintaining their traditional investigation and diagnostic methods, rather that experimenting with new ones even if supported by the most recent technological discoveries.

\section{iii. Unavailability of the required ICT infrastructure for telemedicine (e.g., Internet connec- tion, bandwidth for high speed telecommunications, etc.).}

In most rural areas the required ICT infrastructure can be below minimal acceptable levels, thus impairing any type of connection with remote centers and facilities. Lack of ICT infrastructure is one of the most evident causes of failure in telemedicine systems. Item "Communication requirement" of 
the taxonomy and its values in the studied projects reported in $>$ Table 1 and $>$ Table 2 confirm that ICT infrastructure plays a central role is any telemedicine project in developing countries.

\section{iv. Lack of standards.}

Adoption of standards helps a lot in enabling easy communication between different health care centers. Standards relate to data exchange security, safety, and privacy, too. The adoption of a common standard removes many barriers in developing mid-to-big size projects. Such aspects have been highlighted in the classification proposed for design issues: open source code, interoperable tools, and flexibility are all oriented and would benefit of common standards for message exchange, electronic medical record structure, and so on.

\section{v. Regulatory bodies.}

Telemedicine services across the country and between different countries must be suitably regulated by regulatory bodies. This also may help in the adoption of a common standard or of a common care protocol. Both reusability and technology acceptance, discussed in Section 4, are related to such aspect.

\section{vi. Accreditation of telemedicine service providers.}

Many telemedicine service providers are starting to enter the market. The need of evaluate, validate, and certify the services is arising. To the best of our knowledge, no organization is currently taking care of such accreditation procedures.

\section{vii. Licensed health care professionals.}

In order to avoid malpractice in telemedicine, which can be as common as malpractice in traditional medicine, professionals should be specifically trained for telemedicine, as they do for traditional medicine.

\section{viii. Business models.}

At present, no well identified business model has been defined yet to ensure the sustainability of telemedicine. From a pure economic and business management point of view, such models are relevant also in order to estimate costs, revenues, and return of investments.

\section{ix. Reimbursement.}

Would a patient be taken care of by using a telemedicine system, insurance claims may not cover such circumstances as the delivered healthcare service does not follow traditional techniques. That is, a limited or even null reimbursement is provided to insured people if they resort to telemedicine services. Such a discrimination occurs very seldom in developing countries, where generally no health care insurance exists: however, such an aspect must be considered when developing telemedicine systems and services. These last four aspects all relate to the complex issue of "Technology acceptance" we introduced and discussed in the classification proposed for design issues.

\subsubsection{Major Recommendations}

Major recommendations on how to plan, manage, and continue future telemedicine projects come from the literature $[33,39,57,64]$ and from our direct experiences [16]. It is simple to observe that such recommendations derive from the overview allowed by the proposed taxonomy and from the proposed classification of design issues. They refer to:

\section{i. Set clear goals for the project.}

Selecting clear goals to be achieved by the project is the key issue for success in any project. When facing telemedicine projects, and particularly when project designers are not aware about all the characteristics of the remote environment, some features such as language, culture, local habits, religion, and lack of resources may strongly affect the project. Moreover, project goals must be finetuned with the skills of the remote personnel, and vice-versa. 


\section{ii. Select the proper application medical domain and priorities.}

Domain and priorities would be selected in strict accordance with the major needs of the country where the project is going to be deployed. As an example, major needs in developing countries involve infectious diseases, STD (sexually transmitted diseases), pulmonology, as well as Ebola, more recently. Major needs in developed countries mainly include cardiovascular diseases and traumatology. Setting up a telemedicine project with the proper goal in the wrong country will immediately turn into a failure.

\section{iii. Adopt user-friendly interfaces.}

Even if the use of friendly interfaces is a thumb rule which applies to any domain, when dealing with remote users whose skills may be not at a high level, user interface would be as easier as possible. Personal resistance and opposition to using a computer system is nowadays a completely obsolete problem in developed countries, as young generations are getting more and more connected to the Internet: on the other side, some resistance may persist in mid-to-low profile personnel in developing countries, thus affecting in a negative manner the real adoption of telemedicine systems.

\section{iv. Train the personnel.}

Locally organized courses may significantly increase the overall acceptance of the telemedicine system, thus increasing the overall results. Beyond user-friendly interface, training of personnel is a fundamental step in having the proposed technology accepted, especially when no direct interaction between local and remote physicians is available.

\section{v. Increase the accessibility via telecommunications and Internet connectivity.}

Even the most well designed telemedicine system may result in a low quality system if the connectivity with the remote health care center(s) is poor. On the other side, a mid quality system fed by a very good connectivity may produce high quality results.

\section{vi. Foster continuing use.}

While it is quite easy to have the system used at its early stage, mid-term and long-term analysis highlight that after the initial enthusiastic approach, the everyday practice forgets about the telemedicine system. It is advisable to strongly encourage, involve and motivate local personnel in continuing using the systems, even after the first enthusiasm has been consumed. Additional economic funds, taken from the original budget, might be saved to keep the project alive and running for a long time.

\section{vii. Motivate and stimulate shy or touchy users.}

It would be clear to all the personnel involved in the telemedicine project that asking for a remote consultation does not mean lack of skill, incompetence, or inadequacy in managing the patient. Confronting one's opinion with someone's else helps to better analyze and diagnose the patient's disease - no matter if in a developed or developing country.

viii. Implement standards and protocols, consider practices and guidelines.

As already mentioned, adopting standards, shared protocols and guidelines helps a lot in enabling easy communication between different health care centers. More health care centers can easily join the project if widely diffused standards, protocols, guidelines have been adopted, thus not needing to adjust communications or to convert data and information. Moreover, adopting standards eases security, safety, and privacy in sharing data, overtaking many entrance-barriers in developing mid-tobig size projects.

\section{ix. Define a suitable duration for the project.}

Typically, projects are funded for a period of three years, and then the deployed telemedicine service needs to be evaluated and, eventually, to be continued or discontinued [59]. Large-scale projects require more time to be completed and to be evaluated, and thus are more prone to failures then small-scale and agile projects. Again, choosing the proper application domain as well as the goals of the project is an extremely relevant issue. 


\begin{abstract}
x. Start small, then escalate up.
E-mail (asynchronous communication) is a very good starting point for telemedicine projects in poor countries. E-mail communication is cheap, hardware and software requirements are simple, and the information transmission could be in store and forward mode [35]. After the original impact, the service can be extended and enriched, so that more complete services (synchronous communication), more cases and more pathologies (requiring additional information such as signals, sounds, and images), more patients (increased number of managed patients), more personnel (additional physicians and nurses) will be involved. This could be summarized a "start small, then extend and enrich".
\end{abstract}

\title{
xi. Measure cost-effectiveness and user satisfaction.
}

Even though such parameters are hardly measured, at the end of the initial stage of the project some conclusions must be drawn. Particularly, due to the high costs generally requested in telemedicine projects, the decision of continuing or discontinuing the project requires some cost-effectiveness and user satisfaction metrics. Suitable indicators must be defined at project onset, to take then the most appropriate decisions.

\subsubsection{Lessons Learnt}

When designing a computer system in general, all the good practices suggested by the software engineering techniques must be followed. When designing a telemedicine system, some more good practices must be followed, considering the critical aspects typical of the application domain (e.g., in some situations there is no way of applying an undo mechanism, some situations are irreversible, or some decision must be taken in a short time and with partially available data) and that potential users may be not skilled as needed or as advisable. Furthermore, designing a telemedicine system to a target of a developing country, that is with some more difficulties e.g., coming from the technological or the social environment, is even harder.

The major pitfalls in telemedicine systems, especially those deployed in a developing country, include - but are not limited to:

\section{i. Disregarding local habits (both medical as well as cultural and religious ones).}

Introducing some techniques which strongly differ from the local practices or that may result as offending according to the local habits or religion, must be absolutely avoided, or the project will fail even before its start.

\section{ii. Not providing the users with the proper training in ICT in general and with the specific adopted system.}

While it is reasonably expected that any physician in a developed country is familiar with using a $\mathrm{PC}$, such a requisite cannot be given for sure in a developing country.

iii. Abandoning the local users after releasing the system, without providing them with a continual assistance, training and guidance.

In fact, the initial enthusiasm may hide some critical aspects, which - after having become evident may endanger the continuing use of the system.

\section{Conclusions}

In this paper we proposed a survey of main literature dealing with telemedicine projects in developing countries. The study of literature allowed us to propose a taxonomy of these projects that explicitly considers their specific features with respect to telemedicine in developed countries. After the introduction of the taxonomy we then focused on specific design issues developers have to deal with. Such issues have been identified by integrating information from literature (which is often not completely detailed) with some direct experience we recently gained on the field. As a result, we provided some classification criteria for such design issues. Integrating results from the analysis of the literature with some direct experience would allow to bridge the gap between the "abstract" dis- 
cussion of literature and the technical and practical needs to face when designing a real world telemedicine software for developing countries.

\section{Statement on Conflicts of Interest}

The authors declare that they have no conflicts of interest in the research.

\section{Human Subject Research Approval}

Human and/or animal subjects were not included in the work.

\section{Clinical Relevance Statement}

The literature considers many projects in the field of telemedicine. By this paper, we focus on those telemedicine projects devoted to emerging or to developing countries. Most of these projects aim at taking care of patients in critical conditions, which can be treated only by a remote assistance. We both propose a taxonomy to classify projects and provide the reader with major suggestions on how to design a telemedicine project to be deployed in emerging or developing countries. 


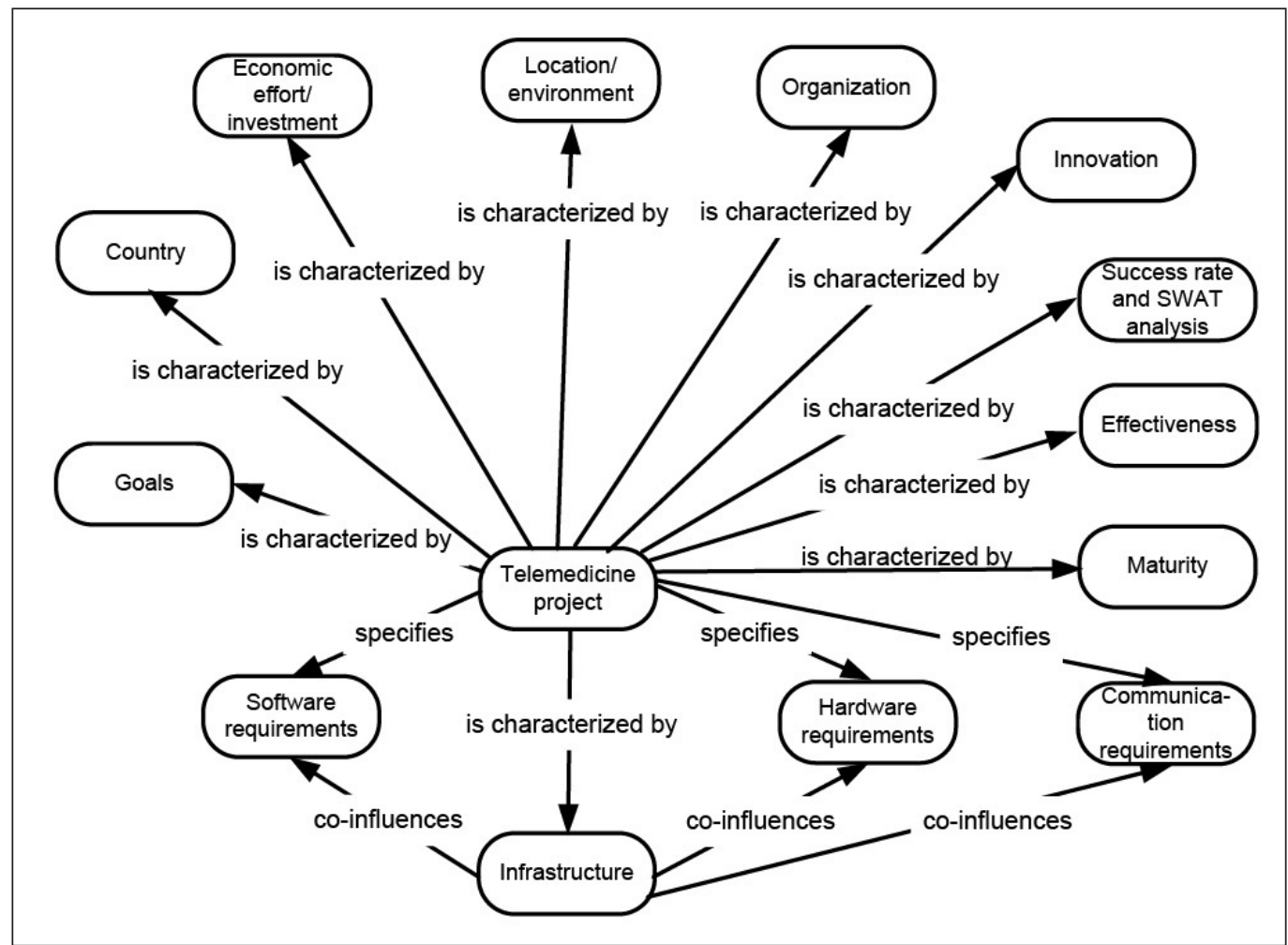

Fig. 1 The concept map of the proposed taxonomy. Relation "co-influences" to requirements has been depicted only from the concept "Infrastructure", but it holds for all the concepts a Telemedicine project is characterized by.

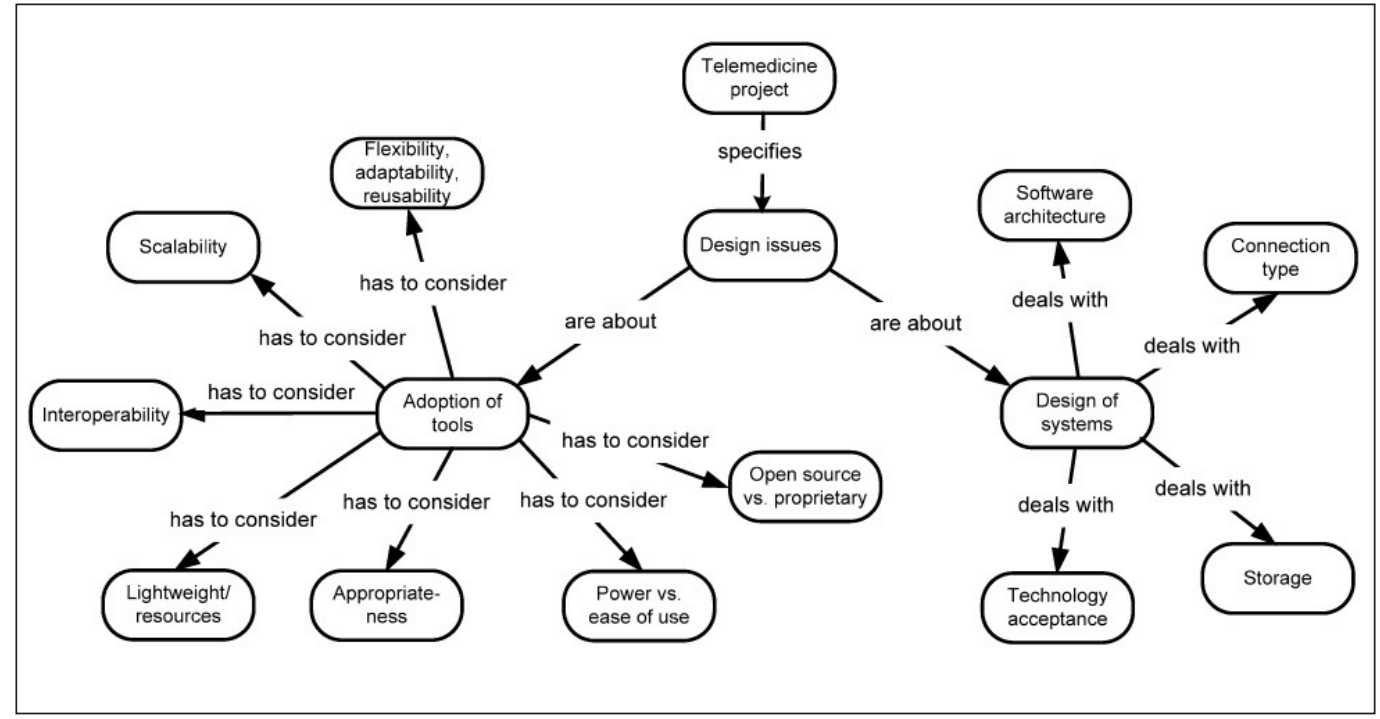

Fig. 2 The concept map of the classification discussed for design issues. 
Table 1 Main categorization dimensions for the projects of Section 3.1. Data about one country consider all the telemedicine projects active in that country - if more than one exist. The economic efforts (\% of GDP and \% of population) refer to the global expenditure/coverage for all the health services in that country. "N/A" stands for "not available/not applicable".

\begin{tabular}{|c|c|c|c|c|c|c|c|}
\hline Dimension & Subdimension & China & India & SSA & Egypt & Pacific Isl. & Amazonia \\
\hline \multirow[t]{4}{*}{ Goal } & remote diagnosis & Y & Y & Y & Y & Y & Y \\
\hline & remote monitoring & $\mathrm{N}$ & N & $\mathrm{N}$ & $\mathrm{N}$ & $\mathrm{N}$ & $\mathrm{N}$ \\
\hline & remote intervention & $\mathrm{N}$ & $N$ & $\mathrm{~N}$ & $\mathrm{~N}$ & $\mathrm{~N}$ & N \\
\hline & remote education & $\mathrm{N}$ & $\mathrm{N}$ & Y & Y & Y & Y \\
\hline Country & $\begin{array}{l}\text { [E]merging or [D]evelop- } \\
\text { ing }\end{array}$ & $\mathrm{E}$ & $E$ & D & D & D & D \\
\hline \multirow[t]{2}{*}{ Economiceffort } & $\%$ of GDP & N/A & 4.9 & 1.0 & $N / A$ & 5.0 & N/A \\
\hline & $\begin{array}{l}\% \text { of population (cover- } \\
\text { age) }\end{array}$ & 70 & 70 & N/A & $N / A$ & 50 & low \\
\hline Location & [U]rban or [R]ural & $\mathrm{R}$ & $\mathrm{R}$ & $\mathrm{R}$ & U & $\mathrm{R}$ & $\mathrm{R}$ \\
\hline \multirow[t]{2}{*}{ Infrastructure } & general & good & mid & poor & good & poor & poor \\
\hline & technology & good & mid & poor & mid & poor & poor \\
\hline \multirow[t]{3}{*}{ Organization } & physicians & Y & $Y$ & Y & Y & Y & Y \\
\hline & nurses & Y & Y & Y & Y & N & Y \\
\hline & other resources & N/A & N/A & N/A & $N / A$ & N/A & N/A \\
\hline Maturity & - & good & mid & $N / A$ & good & mid & low \\
\hline Success rate & - & good & good & N/A & good & mid & mid \\
\hline Effectiveness & - & high & mid & $N / A$ & high & mid & mid \\
\hline Innovation & - & mid & low & low & low & low & low \\
\hline \multirow[t]{3}{*}{ Hardware } & power consumption & high & mid & mid & high & low & low \\
\hline & number of workstations & high & low & low & high & low & low \\
\hline & number of hospitals & high & high & low & high & low & low \\
\hline \multirow[t]{3}{*}{ Com.requirement } & bandwidth & high & high & mid & high & low & low \\
\hline & $\begin{array}{l}{[\mathrm{T}] \text { ext / [S]ound/ [I]mage }} \\
\text { / [V]ideo }\end{array}$ & TSIV & TSIV & $\mathrm{TI}$ & TSI & $\mathrm{T}$ & $T$ \\
\hline & multipoint & Y & Y & Y & Y & N & N \\
\hline \multirow[t]{2}{*}{ Software } & local server/LAN & LAN & LAN & No & LAN & none & none \\
\hline & [0]pen or [P]roprietary & $\mathrm{N} / \mathrm{A}$ & N/A & N/A & N/A & none & none \\
\hline
\end{tabular}


Table 2 Main categorization dimensions for the projects of Section 3.2. Data about one country consider all the telemedicine projects active in that country - if more than one exist. The economic efforts (\% of GDP and \% of population) refer to the global expenditure/coverage for all the health services in that country. "N/A" stands for "not available/not applicable".

\begin{tabular}{|c|c|c|c|c|c|c|c|}
\hline Dimension & Subdimension & Brazil & Zambia & Balkans & ZCM & Burundi & West Africa \\
\hline \multirow[t]{4}{*}{ Goal } & $\begin{array}{l}\text { remote diag- } \\
\text { nosis }\end{array}$ & $\mathbf{Y}$ & $Y$ & $\mathbf{Y}$ & Y & Y & Y \\
\hline & remote monitoring & $\mathrm{N}$ & $\mathrm{N}$ & $\mathrm{N}$ & $\mathrm{N}$ & $\mathrm{N}$ & $\mathrm{N}$ \\
\hline & remote intervention & $\mathrm{N}$ & $\mathrm{N}$ & partial & $\mathrm{N}$ & $\mathrm{N}$ & $\mathrm{N}$ \\
\hline & remote education & $\mathrm{N}$ & $\mathrm{N}$ & Y & Y & Y & Y \\
\hline Country & $\begin{array}{l}\text { [E]merging } \\
\text { or [D] eveloping }\end{array}$ & $E$ & D & D & D & D & D \\
\hline \multirow{2}{*}{$\begin{array}{l}\text { Economic ef- } \\
\text { fort }\end{array}$} & $\%$ of GDP & N/A & N/A & N/A & N/A & N/A & N/A \\
\hline & $\begin{array}{l}\% \text { of population } \\
\text { (coverage) }\end{array}$ & 1.82 & $\mathrm{~N} / \mathrm{A}$ & N/A & $\mathrm{N} / \mathrm{A}$ & 1.5 & N/A \\
\hline Location & {$[\mathrm{U}] \mathrm{rban}$ or [R]ural } & $\mathrm{R}$ & $\mathrm{R}$ & $U$ & U & $U+R$ & U \\
\hline \multirow[t]{2}{*}{ Infrastructure } & general & mid & poor & poor & poor & poor & poor \\
\hline & technology & mid & poor & poor & poor & poor & poor \\
\hline \multirow[t]{3}{*}{ Organization } & physicians & Y & Y & Y & Y & Y & Y \\
\hline & nurses & Y & Y & Y & Y & Y & Y \\
\hline & other resources & Y & & $\mathrm{N}$ & $\mathrm{N}$ & tech. & N \\
\hline Maturity & - & good & good & good & good & good & good \\
\hline Success rate & - & good & mid & good & mid & mid & good \\
\hline Effectiveness & - & good & mid & mid & mid & good & good \\
\hline Innovation & - & low & low & low & low & mid & low \\
\hline \multirow[t]{3}{*}{ Hardware } & power consumption & mid & low & mid & mid & mid & low \\
\hline & $\begin{array}{l}\text { number of work- } \\
\text { stations }\end{array}$ & mid & low & mid & low & mid & low \\
\hline & number of hospitals & 22 & 1 & low & low & 1 & mid \\
\hline \multirow{3}{*}{$\begin{array}{l}\text { Com. require- } \\
\text { ment }\end{array}$} & bandwidth & mid & mid & mid & mid & mid & mid \\
\hline & $\begin{array}{l}\text { [T]ext } \\
\text { / [S]ound/ [I]mage } \\
\text { / [V]ideo }\end{array}$ & TSIV & $\mathrm{TI}$ & TIV & $\mathrm{TI}$ & TIV & N/A \\
\hline & multipoint & $\mathrm{N}$ & $\mathrm{N}$ & $\mathrm{N}$ & Y & $\mathrm{N}$ & Y \\
\hline \multirow[t]{2}{*}{ Software } & local server/LAN & N/A & No & LAN & LAN & LAN & LAN \\
\hline & $\begin{array}{l}\text { [0]pen or [P]roprie- } \\
\text { tary }\end{array}$ & N/A & N/A & 0 & N/A & 0 & 0 \\
\hline
\end{tabular}




\section{References}

1. World Health Organization. Telemedicine: opportunities and developments in Member States: report on the second global survey on eHealth. Global Observatory for eHealth Series, 2, World Health Organization. 2009.

2. Ingenerf J. Telemedicine and terminology: different needs of context information. IEEE Trans Inf Technol Biomed 1999; 3(2): 92-100.

3. Wootton R, Geissbuhler A, Jethwani K, Kovarik C, Person DA, Vladzymyrskyy A, et al. Comparative performance of seven long-running telemedicine networks delivering humanitarian services. J Telemed Telecare 2012; 18(6): 305-311.

4. Istepanian RSH. Telemedicine in the United Kingdom: current status and future prospects. IEEE Trans Inf Technol Biomed 1999; 3(2): 158-159.

5. Joseph V, West RM, Shickle D, Keen J, Clamp S. Key challenges in the development and implementation of telehealth projects. J Telemed Telecare 2011; 17(2): 71-77. doi:10.1258/jtt.2010.100315.

6. Lamminen H, Sernberg V, Ruohonen K, Roine R. A three-year follow-up of Finnish telemedicine programs. IEEE Trans Inf Technol Biomed 2001; 5(2): 174-177.

7. Lakovidis I, Pattichis CS, Schizas C. Guest editorial special issue on emerging health telematics applications in Europe. IEEE Trans Inf Technol Biomed 1998; 2(3): 110-116.

8. Hsieh J, Hsu M. A cloud computing based 12-lead ECG telemedicine service. BMC Med Inf and Decision Making 2012; 12: 77. doi:10.1186/1472-6947-12-77.

9. Istepanian RSH. Guest editorial special issue on mobile telemedicine and telehealth systems. IEEE Trans Inf Technol Biomed 2000; 4(3): 194.

10. Bahaadinbeigy K, Yogesan K, Wootton R. A survey of the state of telemedicine in Western Australia. J Telemed Telecare 2010; 16(4): 176-180.

11. Comyn G. Telemedicine for the benefit of patients, healthcare systems and society. - COM (2008) 689, Nov 4th, 2008. 2008. Available from: http://eur-lex.europa.eu/legal-content/EN/ALL/ ?uri=celex:52008DC0689

12.BCC Research. Global markets for telemedicine technologies, report code: Hlc014f. 2014. Available from: http://www.bccresearch.com/market-research/healthcare/telemedicine-technologies-hlc014f.html\#gsc. $\mathrm{tab}=0$

13. Mordor Intelligence. Global Telemedicine Market - Growth, Trends and Forecasts (2015-2020). 2015. Available from: http://www.mordorintelligence.com/industry-reports/global-telemedicine-market-indus try\#tab-1

14. Wootton R. Telemedicine and developing countries-successful implementation will require a shared approach. J Telemed Telecare 2001; 7.

15. Wang TT, Li JM, Zhu CR, Hong Z, Hong-Yu Yang DMA, Ren JC, et al. Assessment of utilization and costeffectiveness of telemedicine program in western regions of China: A 12-year study of 249 hospitals across 112 cities. Telemed J E Health 2016; 22(11): 1-12. doi:10.1089/tmj.2015.0213.

16. Combi C, Pozzani G, Pozzi G. Design, development, deployment of a telemedicine system in a developing country: Dealing with organizational and social issues. In 2015 International Conference on Healthcare Informatics, ICHI 2015, Dallas, TX, USA, October 21-23, IEEE Computer Society 2015; 545-554. doi:10.1109/ICHI.2015.103.

17.US National Library of Medicine, National Institutes of Health. PubMed. 2016. Available from: https://www.ncbi.nlm.nih.gov/pubmed.

18.Ley M. DBLP - Computer Science Bibliography [Internet]. 2016. Available from: http://dblp.uni-trier.de/.

19. Tulu B, Chatterjee S, Laxminarayan S. A taxonomy of telemedicine efforts with respect to applications, infrastructure, delivery tools, type of setting and purpose. In 38th Hawaii International Conference on System Sciences (HICSS-38 2005), CD-ROM / Abstracts Proceedings, 3-6 January 2005, Big Island, HI, USA. IEEE Computer Society. doi:10.1109/HICSS.2005.56.

20.Tulu B, Chatterjee S, Maheshwari M. Telemedicine taxonomy: A classification tool. Telemed J E Health 2007; 13(3): 349-353. doi:10.1089/tmj.2006.0055.

21. Beltrame F, Boddy K, Maryni P. Adopting telemedicine services in the airline framework. IEEE Trans Inf Technol Biomed 2001; 5(2): 171-174.

22. Anogianakis G, Maglavera S, Pomportsis AS. Relief for maritime medical emergencies through telematics. IEEE Trans Inf Technol Biomed 1998; 2(4): 254-260.

23. Chimiak WJ, Rainer RO, Chimiak JM, Martinez R. An architecture for naval telemedicine. IEEE Trans Inf Technol Biomed 1997; 1(1): 73-79.

24. The World Bank. The World Bank - Working for a World Free of Poverty [Internet]. 2016. Available from: http://www.worldbank.org/ 
25. European Commission, Digital Agenda for Europe. eHealth Action Plan 2012-2020: Innovative healthcare for the 21st century. 2012. Available from: https://ec.europa.eu/digital-agenda/en/news/ehealth-actionplan-2012-2020-innovative-healthcare-21st-century

26. The World Bank. Health expenditure, public (\% of GDP). 2016. Available from: http://data.worldbank.org/indicator/SH.XPD.PUBL.ZS

27. Martìnez A, Villarroel V, Seoane J, del Pozo F. Analysis of information and communication needs in rural primary health care in developing countries. IEEE Trans Inf Technol Biomed 2005; 9(1): 66-72.

28. Martìnez A, Villarroel V, Seoane J, del Pozo F. Rural telemedicine for primary healthcare in developing countries. IEEE Technol Soc Mag 2004; 23(2): 13-22.

29. The World Bank. Fact sheet: Infrastructure in sub-Saharan Africa. 2014. Available from: http://go.worldbank.org/SWDECPM5S0

30. Wootton R. The possible use of telemedicine in developing countries. J Telemed Telecare 1997; 3(1): 23-26.

31. Martìnez A, Villarroel V, Seoane J, del Pozo F. A study of a rural telemedicine system in the Amazon region of Peru. J Telemed Telecare 2004; 10: 219-225.

32. Odutola AB. Developing countries must invest in access to information for health improvements. J Med Internet Res 2003; 5(1): e5. doi:10.2196/jmir.5.1.e5.

33. Rodrigues RJ, Risk A. eHealth in Latin America and the Caribbean: development and policy issues. J Med Internet Res 2003; 5(1): e4. doi:10.2196/jmir.5.1.e4.

34. Parent F, Coppieters Y, Parent M. Information technologies, health, and „globalization“: anyone excluded? J Med Internet Res 2001; 3(1): E11. doi: 10.2196/jmir.3.1.e11.

35. Meso P, Mbarika VWA, Sood SP. An overview of potential factors for effective telemedicine transfer to Sub-Saharan Africa. IEEE Trans Inf Technol Biomed 2009; 13(5): 734-739.

36. Moodley D, Pillay AW, Seebregts CJ. Position paper: Researching and developing open architectures for national health information systems in developing African countries. In Liu Z, Wassyng A, editors, FHIES, volume 7151 of Lecture Notes in Computer Science. Springer, pp. 129-139.

37. Bai J, Hu B, Zhang Y, Ye D. A communication server for telemedicine applications. IEEE Trans Inf Technol Biomed 1997; 1(3): 205-209.

38. Xue Y, Liang H. Analysis of telemedicine diffusion: The case of China. IEEE Trans Inf Technol Biomed 2007; 11(2): 231-233.

39. Pal A, Mbarika VWA, Payton FC, Datta P, McCoy S. Telemedicine diffusion in a developing country: The case of India (March 2004). IEEE Trans Inf Technol Biomed 2005; 9(1): 59-65.

40. Hussein R, Khalifa A. Telemedicine in Egypt: SWOT analysis and future trends. GMS Medizinische Informatik, Biometrie und Epidemiologie 2012; 8(1): 1-16.

41. Bice SD, Dever G, Mukaida L, Norton SA, Samisone J. Telemedicine and telehealth in the Pacific islands region: A survey of applications, experiments, and issues. In Peacesat. Pacific Telecommunications Council, pp. 574-581.

42. Norton SA, Floro C, Bice SD, Dever G, Mukaida L, Scott JC. Telemedicine in Micronesia. Telemed J 1996; 2(3): 225-231.

43. da Silva Mattos S, Hazin SMV, Regis CT, de Araújo JSS, de Lira Albuquerque FC, Moser LRDN, et al. A telemedicine network for remote pediatric cardiology services in North-East Brazil. Bulletin of the World Health Organization 2015; 93(12): 881-887.

44.Nexus Mundi Foundation. Chikuni Mission Hospital. 2014. Available from: http://s328691085.onlinehome.us/

45. Gori A, Taddei A, Mota D, Rocca E, Carducci T, Piccini G, et al. Open source teleconsulting system for international cooperative medical decision making in congenital heart diseases. Comput Cardiol 2010; 37: 481-484.

46.Patologi Oltre Frontiera. Available from: http://www.apof.eu/

47. Geissbuhler A, Ly O, Lovis C, L'Haire JF. Telemedicine in Western Africa: lessons learned from a pilot project in Mali, perspectives and recommendations. In AMIA Annual Symposium Proceedings, volume 2003. American Medical Informatics Association, p.249.

48. Bagayoko CO, Muller H, Geissbuhler A. Telemedicine network in French-speaking Africa (RAFT). In Medical Imaging and Telemedicine. pp. 108-113.

49. Bagayoko CO, Muller H, Geissbuhler A. Assessment of Internet-based tele-medicine in Africa (the RAFT project). Comput Med Imaging Graph 2006; 30(6): 407-416.

50. Geissbuhler A, Bagayoko CO, Ly O. The raft network: 5 years of distance continuing medical education and tele-consultations over the internet in French-speaking Africa. I J Medical Informatics 2007; 76(5-6): 351-356.

51.Fondazione Don Carlo Gnocchi ONLUS. SIERRA LEONE - Sostegno all'Holy Spirit Hospital di Makeni: formazione del personale, rafforzamento attivit_a di diagnostica e telemedicina, coordinamento presenze 
equipe chirurgiche internazionali. 2014. Available from: http://www.dongnocchi.it/solidariet\%C3\%A0-in ternazionale/siamo-stati-anche-in/sierra-leone/sierra-leone-1/sostegno-all-holy-spirit-hospital-di-makeni- 1.3373

52. Fondazione CUMSE. Progetto telemedicina. 2013. Available from: http://www.cumse.it/progetti-in-africa/ progetti-realizzati/progetto-telemedicina/

53. Shiferaw F, Zolfo M. The role of information communication technology (ICT) towards universal health coverage: the first steps of a telemedicine project in Ethiopia. Global Health Act 2012; 5.

54. Nchise A, Boateng R, Mbarika V, Saiba E, Johnson O. The challenge of taking baby steps | preliminary insights into telemedicine adoption in Rwanda. Health Policy Technol 2012; 1(4): 207 - 213. doi:10.1016/j.hlpt.2012.10.004.

55. Deglise C, Suggs SL, Odermatt P. Short message service (SMS) applications for disease prevention in developing countries. J Med Internet Res 2012; 14(1): e3. doi:10.2196/jmir.1823.

56. Patterson V, Swinfen P, Swinfen R, Azzo E, Taha H, Wootton R. Supporting hospital doctors in the Middle East by email telemedicine: something the industrialized world can do to help. J Med Internet Res 2007; 9(4): e30. doi:10.2196/jmir.9.4.e30.

57. Bhatta R, Aryal K, Ellingsen G. Opportunities and Challenges of a Rural-telemedicine Program in Nepal. J Nepal Health Res Counc 2015; 13(30): 149-153.

58. Chan CV, Kaufman DR. A technology selection framework for supporting delivery of patient-oriented health interventions in developing countries. J Biomed Inform 2010; 43(2): 300-306.

59. Holle R, Zahlmann G. Evaluation of telemedical services. IEEE Trans Inf Technol Biomed. 1999; 3(2): 84-91.

60. Ekeland AG, Bowes A, Flottorp S. Effectiveness of telemedicine: A systematic review of reviews. I J Medical Informatics 2010; 79(11): 736-771.

61. Ekeland AG, Bowes A, Flottorp S. Methodologies for assessing telemedicine: A systematic review of reviews. I J Medical Informatics 2012; 81(1): 1-11.

62. Chen W, Akay M. Developing EMRs in developing countries. IEEE Trans Inf Technol Biomed 2011; 15(1): 62-65.

63. Czekierda L, Masternak T, Zielinski K. Evolutionary approach to development of teleconsultation system for imaging medicine. IEEE Trans Inf Technol Biomed 2012; 16(4): 550-560.

64. Shiferaw F, Zolfo M. The role of information communication technology (ICT) towards universal health coverage: the first steps of a telemedicine project in Ethiopia. Global Health Act 2012; 5. 